Research Article

\title{
Impact of educational intervention on pressurized metered dose inhaler technique among undergraduate medical students
}

\author{
Nalini G. K.*, Jayashree V. Nagaral, Sahana K. Hebbar, Sahana G. N., \\ Deepak P., Kavitha $S$.
}

Department of Pharmacology, Hassan Institute of Medical Science, Hassan, Karnataka, India

Received: 09 July 2016 Accepted: 09 August 2016

*Correspondence to:

Dr. Nalini G. K.,

Email: drnalinigk72@

yahoo.com

Copyright: (C) the author(s), publisher and licensee Medip Academy. This is an openaccess article distributed under the terms of the Creative Commons Attribution NonCommercial License, which permits unrestricted noncommercial use, distribution, and reproduction in any medium, provided the original work is properly cited.

\begin{abstract}
Background: Inhaled medications form the cornerstone for the management of Asthma and related diseases. Proper technique of pressurized metered dose Inhalers (pMDIs) has proven to be associated with higher level of control of these conditions. Medical personnel who are responsible for training patients must themselves be proficient with usage of pMDI. This study evaluated the outcome of different educational interventions regarding the correct usage of pMDI.

Methods: An interventional study was carried out with 60 second year medical students in department of pharmacology, HIMS, Hassan from June to August 2015. Pre and post intervention (after one week and one month) was evaluated based on National Asthma Education and Prevention Program (NAEPP) criteria for the use of pMDI by written and demonstration methods. The interventions included a video clip, an information leaflet and demonstration by a trained faculty.

Results: Overall mean scores in pre-test for written knowledge and skill demonstration are $2.13 \pm 1.49$ and $3.78 \pm 1.06$.There was substantial improvement in post intervention scores $7.15 \pm 1.41$ and $7.37 \pm 1.67(\mathrm{p}<0.05)$. Using one way ANOVA, demonstration group has shown statistically significant improvement in mean score compared to video and checklist groups in 1 week (8.8 versus 7.2 and $6.1, \mathrm{p}<0.05)$ and 1 month $(8.25$ versus 7.1 and $5.7(\mathrm{p}<0.05)$ after the intervention.

Conclusions: Correct usage of pMDI is a necessary skill for health care professionals and can be taught by various methods. The educational intervention by an interactive demonstration has proven to be effective in learning the inhaler technique.
\end{abstract}

Keywords: Education, Intervention, pMDI, Medical students

\section{INTRODUCTION}

Asthma and chronic obstructive pulmonary disease (COPD) represent the leading chronic respiratory diseases in the world, owing to their high prevalence and burden on the health system. ${ }^{1}$ Treatment of pulmonary disease with inhaled aerosol drugs with correct inhalational technique offers advantages over systemic therapy, including a more rapid onset, optimal drug delivery with lower dose and minimal adverse effects, because of direct targeting of the lungs. ${ }^{2}$ However, erroneous inhalation technique is very common in patients with chronic airflow obstruction.
The key concern in this scenario is that healthcare professionals often attribute lack of clinical efficacy with the pharmacological properties of the drug, rather than the inability of the patient to use the inhalation device properly. Consequently, doctors increase the drug dose delivered to the patient, leading to the potential for greater toxicity and adverse side-effects, which could have been avoided by attending to the patient-device interaction. ${ }^{4}$

In order to improve treatment outcome, healthcare professionals should teach the patients about correct use of pMDI. 
The technical mistakes are not limited to the patients; some data indicate that health care providers have been shown to have suboptimal MDI technique. ${ }^{5}$ Various studies from different countries have recommended training programs in order to improve their knowledge about the correct use of inhalers. ${ }^{6-8}$ As future physicians, the undergraduate medical students should be proficient in their approach to patient counseling and develop skills needed to deliver optimal education to patients.

Keeping in mind the significance of asthma education and doctor's role, a clinical project regarding asthma education among medical students was undertaken in department of Pharmacology to teach medical students of Hassan. Clinical observations and documentation/reviews made during clinical rounds revealed that professionals lack the knowledge and skills related to asthma management and inhaler technique and care. Moreover, it has been noticed that during medication administration, did not provide adequate information about inhalers due to which, treatment failure of the patient. Therefore, a need was felt to train students for better management and care of asthmatic patients. Hence, the present study has been conducted to evaluate the written knowledge and demonstration skill by different educational interventions regarding the correct usage of MDI among undergraduate medical students.

\section{METHODS}

\section{Study design and setting}

An interventional study was conducted in the Department of Pharmacology from June to August 2015, Hassan institute of medical sciences, Hassan. In three phases, pre-intervention, intervention and post-intervention. The pre intervention test was immediately followed by educational intervention. The post intervention test was conducted at 1 week and 1 month gap after the intervention. The protocol was approved by the Institutional Ethics Committee.

Table 1: Steps as per NAEPP criteria.

\begin{tabular}{|l|}
\hline \multicolumn{1}{|c|}{ Steps } \\
\hline Remove the cap \\
\hline Shake the inhaler several times \\
\hline $\begin{array}{l}\text { Stand and hold head up straight, holding the inhaler in } \\
\text { a mouth-piece down position }\end{array}$ \\
\hline Exhale all the way until you can breathe out no more \\
\hline $\begin{array}{l}\text { Place the mouth piece between your teeth and close } \\
\text { your lips, don't block the opening with your mouth }\end{array}$ \\
\hline $\begin{array}{l}\text { While breathing in deeply and slowly depress the top } \\
\text { of the metal canister to release a dose }\end{array}$ \\
\hline Continue to breathe in slowly over 4-5 second \\
\hline Hold your breath for 10 second \\
\hline Breathe out slowly \\
\hline
\end{tabular}

\section{Participants' selection and sample size}

About 60 second year undergraduate medical students willing to participate were included in our study with their verbal consent. All the participants were instructed to attend all the phases of the study. The tools of this study was scoring of the inhalation technique was done as per National Asthma Education and Prevention Program (NAEPP) criteria given in Table 1.

\section{Operational modality and study tool}

Using simple randomization technique, all 60 participants were categorized into three groups with 20 students in each. The participants were asked to write and demonstrate the use of the placebo pMDI and the steps were graded as per the NAEPP criteria (Table 1). ${ }^{9}$ Immediately following the pre-test, the participants were educated about the proper use of pMDI. The educational intervention was carried out separately for all the three groups by trained staff.

- Group 1 was given the leaflet

- Group 2 was shown a video clip

- Group 3 underwent interactive demonstration on inhalation technique

After the intervention, the assessment of written and skill performance was done at one week and one month interval.

\section{Assessment of inhaler techniques}

All the participants were asked to demonstrate the technique by using placebo metered dose inhaler. The accuracy of the participants was evaluated by a standard checklist. For every correctly carried out step, a score of ' 1 ' was given, and for every incorrect step, a score of ' 0 ' was given. No oral instructions, prompts or critiques were provided by the observers prior to, during, or after the tests. The scores obtained from all the three groups pre and post interventional tests were entered in Microsoft excel spread sheet respectively and analysed.

\section{Statistical analysis}

The mean scores of all the three groups in pre and post intervention test were calculated from the number of correct steps of inhaler use from written and skill based test. The difference in the mean scores of the knowledge and the inhaler use for both pre and post educational intervention were calculated and the level of significance was determined by paired t- test and one way ANOVA test using Graphpad Instat software. Statistical significance is assumed at a level of $\mathrm{p}<0.05$.

\section{RESULTS}

60 participants were included in the analysis of the study. The changes in overall mean score \pm SD among three 
groups during various phases of the study are shown in Table 2.

Table 2: Impact of interventions on overall Mean \pm SD score.

\begin{tabular}{|lll|}
\hline & $\begin{array}{l}\text { Knowledge } \\
\text { score }\end{array}$ & Skill score \\
\hline Pre intervention & $2.13 \pm 0.24$ & $3.78 \pm 0.16$ \\
\hline Post intervention 1 week & $7.14 \pm 1.25$ & $7.37 \pm 1.36$ \\
\hline Post intervention 1 month & $6.62 \pm 1.07$ & $7.02 \pm 1.28$ \\
\hline
\end{tabular}

\section{Pre-intervention phase}

During pre-intervention phase, none of the students had written or demonstrated all the steps correctly for both knowledge and skill scores. There was no significant differences in baseline scores among various groups (Table 2). At baseline, the commonest errors done by the students while demonstrating MDI use were at step 8 (74\%), step $9(51 \%)$ and step $2(18 \%)$.

\section{Effect of interventions}

One week following the intervention, there was overall improvement in the mean score of written and skill scores in all the three groups $(\mathrm{p}<0.05)$ (Table 2 and 3). About $51 \%$ and $40 \%$ of the students attained full scores in knowledge and skill based assessment respectively. One month after the intervention the mean score was not maintained as seen in 1 week of post intervention $(\mathrm{p}<0.05)$.

Table 3: ANOVA between the three groups.

\begin{tabular}{|lllll|}
\hline Post-test interval & Written test & & Demo test & Significance $\mathbf{P}<\mathbf{0 . 0 5}$ \\
\hline 1 week & F value & Significance $\mathbf{P}<\mathbf{0 . 0 5}$ & F value & YES \\
\hline 1 month & 162.4005 & YES & 11.4568 & NO \\
\hline
\end{tabular}

In order to compare the efficiency, the improvement in the score was compared individually for all the three interventions. The mean score improvement observed in the demonstration group is more compared to video and leaflet group. The percentage of students securing full scores were also more in demonstration group.

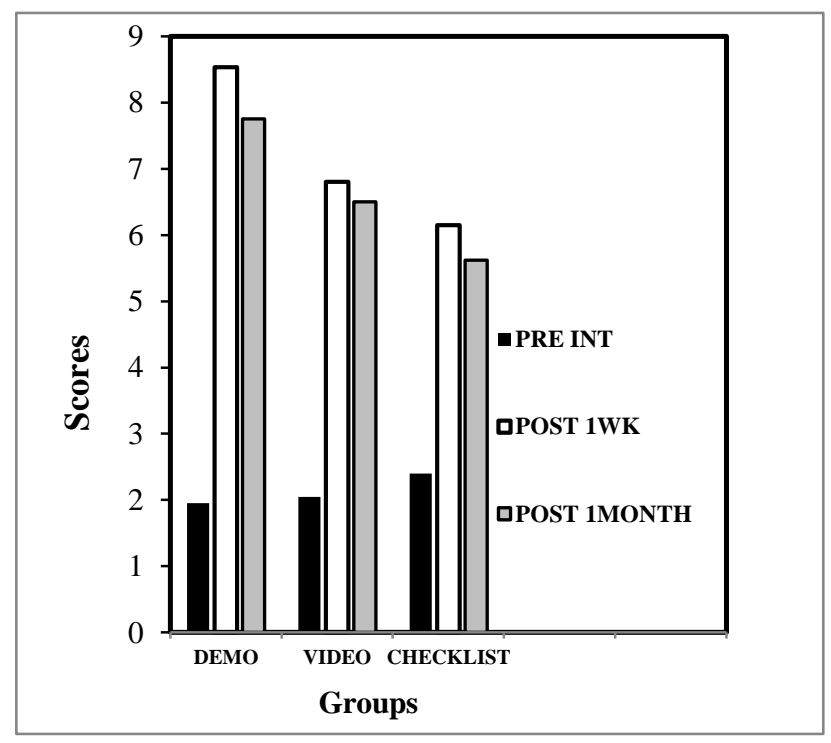

Figure 1: Effect of interventions on knowledge of MDI use.

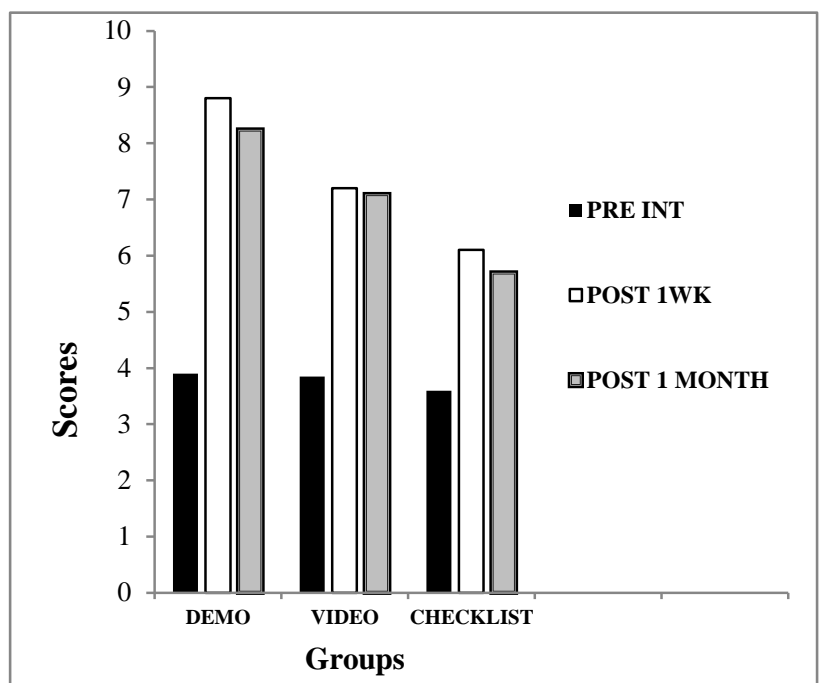

Figure 2: Effect of Interventions on skill of MDI use.

\section{DISCUSSION}

It has been apparent over the past years that the proper use of inhaler devices is not as obvious to patients as taking tablets or capsules by mouth. Surveys have indicated that fewer than half of adult patients with MDI. ${ }^{10}$ or even as few as 10 percent will achieve optimal benefit as a result of inefficient technique. ${ }^{11}$ Hence, intention would be preparing medical students with optimal skills in delivering inhaler technique education to asthma patients. 
However, our study has demonstrated inadequate knowledge among majority of the students in using MDI at base line. The poor performance in the pre intervention scores might be due to lack of knowledge regarding the usage of MDI. These findings are in accordance with other studies by Rekha et al on medical students and Kishore et al among various health professionals showing poor performance before the educational intervention. ${ }^{5,12}$

$90 \%$ students could perform some of the steps of MDI without training for example, removal of the MDI cap (step 1). One participant held the MDI reversely, which implies total lack of awareness regarding MDI usage. The common errors done by the students were at the step" Hold the breath for $10 \mathrm{sec}$ and Breath out slowly" were also seen in other studies. ${ }^{12,13}$ Failure to use a slow and deep inhalation is the most common mistake made by patients using an MDI and is more common than failure of coordination. ${ }^{14} \mathrm{~A}$ faster inhalation rate increases the likelihood of or pharyngeal deposition with an MDI and less drug reaching the lungs. ${ }^{15}$

The improvement in knowledge as well as skill following an educational intervention indicates the effectiveness of various teaching aids. The improvement in mean scores of 1 week after intervention, among demonstration group is better compared to check list and video groups. The difference in the scores among three groups may be due to the fact that some of the critical steps demand higher skill and accuracy like, step 5 "place the mouth piece between your teeth and close your lips, don't block the opening with your mouth" and step 6, "while breathing in deeply and slowly depress the top of the metal canister to release a dose". These steps can be learnt well when the student actually observes the steps being demonstrated rather than reading them and watching a video. The importance of performing every step can be explained and taught by a live demonstration. These findings are consistent with previous studies, wherein a structured educational demonstration achieved a better result compared to provision of instruction pamphlets. ${ }^{16,17}$ In these studies methods used included hand-outs, videotapes on correct inhaler technique and hands on experience with placebo inhalers and assessments were repeated at one to three months after the education was delivered and results showed significant improvement in inhaler technique in the majority of studies. ${ }^{18}$ One month after the intervention, participants didn't show significant improvement in inhaler technique by demonstration method,when compared with baseline and 1 week post intervention scores. However, there is tendency even learned by trained faculty, the demonstration technique with time, will be decreased. This indicates that students need repetition on every educational technique periodically to keep them alert always. So that at time of the day, the professionals will communicate with the patients in an appropriate way to give better doctor patients compliance. In this study, those who failed to achieve full score were subjected to revision of the technique (written Instruction/practical instruction).
Total score may not reflect adequacy of technique. The improvement in the scores following an intervention may not indicate the proper drug delivery through the device, as some essential steps in technique might have been missed. So, attaining full score is the desirable educational outcome. Our study has shown demonstration group has more students with full scores.

A major challenge for medical undergraduates is the application of theoretical knowledge to the management of patients. The written information is not effective in educating students on inhaler demonstration skills, nor is it effective in providing them with the skills needed to transfer their knowledge and skills to their patients.

Limitations of this study were the study has not included patients. Perhaps the improvement in technique might have occurred without any intervention. Only pMDI was evaluated and dry powder inhalers were not included in the current study.

Recommendations of this study was frequent sessions should be organized for students about asthma care, its management and correct inhaler technique. Competence in student's skills should be given high emphasis in curriculum. Further research studies and clinical projects are recommended to be carried out among students and other health care professionals for improved asthma care and its management within the hospital and overall in the country.

\section{CONCLUSION}

This study showed inadequacy of knowledge and insufficient pMDI technique skills at baseline. After intervention by appropriate teaching and learning methods by using relevant tool showed a marked improvement in usage of pMDI in knowledge and skill. a better approach was by interactive demonstration method by a trained teacher. In integrated sessions by problem learning, even the long term effect by intervention showed that the students need to be a lifelong learner and self-directed learners.

\section{ACKNOWLEDGEMENTS}

Authors would like to thankful to second year medical students, teaching and non-teaching staff for their active participation in the study. This study received no financial support from any source. Our special thanks to Dr Sanjiv Lewis our Mentor, Green Lantern group and all the members FIME 2015 'A' batch for their support.

Funding: No funding sources Conflict of interest: None declared

Ethical approval: The study was approved by the Institutional Ethics Committee 


\section{REFERENCES}

1. Souza MLM, Meneghini AC, Ferraz E, Vianna EO, Borges MC. Knowledge of and technique for using inhalation devices among asthma patients and COPD patients. J Bras Pneumol. 2009;35(9):824-31.

2. Rau JL. Practical problems with aerosol therapy in COPD. Respiratory care. 2006;51(2):158-72.

3. Jolly GP, Mohan A, Guleria R, Poulose R, George J. Evaluation of metered dose inhaler use technique and response to educational training department of pulmonary medicine and sleep disorders. All India Institute of Medical Sciences, New Delhi, India; 2014:17-20.

4. Al-Showair RA, Tarsin WY, Assi KH, Pearson SB, Chrystyn H. Can all patients with COPD use the correct inhalation flow with all inhalers and does training help? Respir Med. 2007;101(11):2395-401.

5. Kishore PV, Palaian S, Alam K, Shankar PR, Bajracharya B, Den Ende JV. Correct use of a metered dose inhaler: a prospective interventional study among healthcare professionals in a nepalese teaching hospital. Journal of Clinical and Diagnostic Research. 2008;2(2):720-5.

6. Lee-Wong M, Mayo PH. Results of a programme to improve house staff use of metered dose inhalers and spacers. Postgrad Med J. 2003;79:221-5.

7. Yilmaz A, Bayramgurler B, Akkaya E. Evaluation of the usage techniques of the inhalational devices and the effects of training on Nurses. Turkish Respiratory Journal. 2001;2:16-9.

8. Hanania NA, Wittman R, Kesten S, Chapman KR. Medical personnel's knowledge of and ability to use inhaling devices. Metered dose inhalers, spacing chambers, and breath- actuated dry powder inhalers. Chest. 1994;105:111-6.

9. Baddar SA, Al-Rawas OA, Al-Riyami KA, Worthing EA, Hanssens YI, Taqi AM, et al. Metered-dose inhaler technique among healthcare providers practicing in Oman. SQU Journal for Scientific Research: Medical Sciences. 2001;1:39-43.

10. NAEPP. Expert panel report 2. Guidelines for the diagnosis and management of asthma: NIH publication; 1997.

11. Crompton GK. The adult patient's difficulties with inhalers. Demonstration of appropriate technique and patient observation by health professionals is the most effective means of teaching appropriate inhaler use. Lung. 1990;suppl:658-62.

12. Self TH, Brooks JB, Lieberman P, Ryan MR. The value of demonstration and the role of the pharmacist in teaching the correct use of pressurized bronchodilators. Can Med Assoc J. 1983;128:129-31.

13. Rekha YA, Chetanraj GB, Balasaheb BG, Pradeep KD. Assessment of medical student's knowledge on metered dose inhaler technique and asthma in a tertiary care teaching hospital. Available at www.iosrjournals.org. 2016;11(2):52-7.

14. Dudyala NS, Amarendra MA, Subbarao PV. The use of metered dose inhalers: where are we? Journal of Clinical and Diagnostic Research. 2012;6:612-4.

15. John H, David P, Neil CB, Virchow JC, Nicolas R, Henry C. Choosing inhaler devices for people with asthma: current knowledge and outstanding research needs. Respiratory Medicine CME. 2010;3:125-31.

16. Hardwell A, Barber V, Hargadon T, McKnight E, Holmes J, Levy ML. Technique training does not improve the ability of most patients to use pressurised metered-dose inhalers (pMDIs). Prim Care Respir J. 2011;20(1):92-6.

17. Palen VJ, Klein JJ, Kerkhoff AH, Herwaarden CL, Seydel ER. Evaluation of the long-term effectiveness of three instruction modes for inhaling medicines. Patient Educ Couns. 1997;32(Suppl 1):S87-95.

18. Lindgren S, Bake B, Larsson S. Clinical consequences of inadequate inhalation technique in asthma therapy. Eur J Respir Dis. 1987;70:93-8.

Cite this article as: Nalini GK, Nagaral JV, Hebbar SK, Sahana GN, Deepak P., Impact of educational intervention on pressurized metered dose inhaler technique among undergraduate medical students. Int J Basic Clin Pharmacol 2016;5:2066-70. 